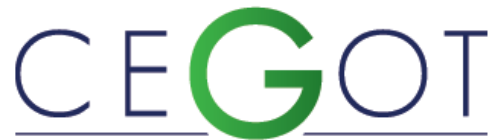

Centro de Estudos de Geografia e Ordenamento do Território
Geografia e Ordenamento do Território, Revista Eletrónica Centro de Estudos de Geografia e Ordenamento do Território http://cegot.org

SILVA, AdRIEL

Universidade Federal de Pelotas - UFPel/Instituto de Ciências Humanas/ICH-UFPel

Av. Juscelino Kubitschek de Oliveira,2200- São Gonçalo, 96075-810, Pelotas, Brasil

adrielcosta09@gmail.com

\author{
LIHTNOV, DIONE \\ Universidade Federal de Pelotas - UFPel/Instituto de Ciências \\ Humanas/ICH-UFPel \\ 96075-810, Pelotas, Brasil \\ lihtnov@gmail.com \\ VIEIRA, SIDNEY \\ Universidade Federal de Pelotas - UFPel/Instituto de Ciências \\ Humanas/ICH-UFPel \\ 96075-810, Pelotas, Brasil \\ sidgeo@hotmail.com
}

\title{
Territorialidades, identidades e permanências: o bairro São Gonçalo na cidade de Pelotas, RS
}

Territorialities, identities and stays: the São Gonçalo quarter in the city of Pelotas, RS

Referência: Silva, Adriel; Lihtnov, Dione; Vieira, Sidney (2018). Territorialidades, identidades e permanências: o bairro São Gonçalo na cidade de Pelotas, RS. Revista de Geografia e Ordenamento do Território (GOT), n. ${ }^{\circ} 15$ (dezembro). Centro de Estudos de Geografia e Ordenamento do Território, p. 387-402, dx.doi.org/10.17127/got/2018.15.016

\section{RESUMO}

O presente texto busca contribuir para a reflexão acerca dos processos de (re)produção do espaço urbano, com estudo de caso em um bairro da cidade de Pelotas, RS. Analisa-se o processo de formação histórica da Região Administrativa São Gonçalo, tendo em vista investigar os impactos da construção de empreendimentos imobiliários voltados para estratos de alta renda naquela área, em meio a um processo de resistência e conflito territorial com os moradores locais. Atrelado a esses fatores, ressalta-se a discussão acerca das territorialidades, identidades e do sentimento de pertencimento ao lugar de vivência destes moradores.

Palavras-chave: Territorialidade. Identidade. Resistência. São Gonçalo. Pelotas.

\section{ABSTRACT}

This paper seeks to contribute to the reflection about the processes of (re) production of the urban space, with case study in a neighborhood of the city of Pelotas, RS. The historical formation process of the São Gonçalo Administrative Region is analyzed in order to investigate the impacts of the construction of real estate projects aimed at high income strata in that area, in the midst of a process of resistance and territorial conflict with the local residents. Linked to these factors, the discussion about the territorialities, identities and the feeling of belonging to the living place of these residents stands out. 
Keywords: Territoriality. Identity. Resistance. Sao Gonçalo. Pelotas.

\section{Pelotas: Uma Introdução Histórica}

O presente artigo partiu do objetivo principal de analisar o processo de re-produção do espaço urbano sob a lógica do capitalismo, para entender como se dá o processo de organização espacial de uma cidade. Com base em um estudo de caso, subsidiariamente se dedicou a analisar como os interesses do capital imobiliário podem aparecer subsumidos em propostas de inovação urbana, que escondem os reais interesses de obenção de lucro. Também se deteve em estudar conflitos gerados entre novos empreendimentos e moradores tradicionais que tendem a ser expulsos de seus locais de moradia. E, procurou demonstar que a atuação do Estado, quando não regula de forma justa os processos sociais de produção da cidade é capaz de promover injustiça social. Para a realização desses objetivos se utilizou a metodologia do estudo de caso, delimitando a área a ser estudada, realizando levantamentos de campo para identificação dos problemas, bem como entrevistas com os sujeitos envolvidos e análise minuciosa das propostas e projetos para a área.

É conhecido dentro dos estudos geográficos o poder estruturador do capital na produção da cidade. No processo de (re)produção do espaço urbano, o capital se (re)produz encontrando meios de se manter hegemônico. E na cidade de Pelotas a história não foi diferente. A cidade traz consigo uma íntima relação com a produção histórica de sua sociedade: a indústria do charque ${ }^{1}$ ao longo do arroio Pelotas e do canal São Gonçalo. Em meados do século XVIII, às margens do canal São Gonçalo, José Pinto Martins constituiu a primeira charqueada na região. A posição geográfica privilegiada, localizada próxima aos rebanhos bovinos (vacarias e campos neutrais), além da proximidade ao porto da cidade de Rio Grande e às vias fluviais (das lagoas Mirim e dos Patos), fez com que a cidade de Pelotas se tornasse o maior centro escravista e charqueador da região sulina. A carne seca, um dos principais itens da alimentação dos escravos, era produzida abastecendo tanto o mercado

\footnotetext{
${ }^{1}$ O charque (em quéchua: charki ou em araucano charqui, carne salgada) é uma carne salgada e seca ao sol com o objetivo de mantê-la própria ao consumo por mais tempo. Tem uma salga e exposição solar maiores que outras carnes dessecadas, sendo empilhado como mantas em lugares secos para desidratação.
} 
externo como o interno. Financiada pelos grandes senhores do charque, a cidade vivenciou um grande desenvolvimento econômico e cultural à época, chegando a ser conhecida, no século XIX, como a "Atenas do Rio Grande do Sul".

O advento e uso da refrigeração como processo industrial para conservação da carne, aliado ao fim da mão de obra escrava, foram fatos coadjuvantes no declínio da economia baseada na produção da carne salgada. Os frigoríficos passaram a conservar a carne em processos cada vez mais vantajosos. Além disso, a produção do charque estava baseada no uso intensivo da mão de obra escrava. Quando a mão de obra passou a ser assalariada não houve adaptação do processo produtivo que pudesse manter a rentabilidade do setor. Pouco a pouco, a vantagem dos grandes rebanhos criados de forma extensiva nos campos do sul do Brasil, passou a ser suplantada pela criação de forma intensiva, sobretudo em novas fronteiras agropecuárias desbravadas, sobretudo, no centro-oeste do país. A cidade e a região não se inseriram com facilidade nos novos arranjos produtivos que surgiram e passaram a experimentar uma fase de estagnação econômica. A economia, antes baseada em único produto, o charque, demandava iniciativas para dinamização da produção. 0 capital oriundo do setor saladeril foi fundamental por implantar na cidade uma série de melhorias urbanas, tais como calçamento, iluminação, transportes, além da produção de um riquíssimo patrimônio arquitetônico. Também propiciou um desenvolvimento industrial, ainda que incipiente, que já apontava para a necessária nova dinâmica de investimento do capital. Assim, surgiram na cidade, curtumes, cervejarias, fábrica de vidro, chapéus, máquinas de escrever, entre outras, como relata Vieira (2005, p. 121).

A partir da industrialização se deu a dinamização do comércio, evidenciando o surgimento de uma fase cuja tônica passava a ser muito mais urbano-industrial do que agráriocomercial. Cresce o setor de abastecimento de gêneros alimentícios e também o de prestação de serviços, adiantando o que viria a ser a tônica dos próximos tempos.

Assim, é possível identificar na cidade, um período de desenvolvimento econômico, que se desenvolve entre os anos de 1780 até 1884, quando já surgem na região os efeitos do fim da escravidão, que é caracterizado pela atividade de produção do charque. Depois, desde a abolição da escravidão e a proclamação da república, até os anos posteriores ao final da II Grande Guerra, a cidade ainda experimenta os frutos da riqueza anterior, já sentindo o impacto gerado pelo declínio do charque e a ascenção da industrialização diversificada e 
pautada na mão de obra assalariada. A partir da década de 1950, o comércio viria a se tornar a principal fonte econômica da cidade, fator que subsiste ao longo do século XXI.

As profundas transformações ocorridas na sociedade, de um modo geral, como a Guerra Fria, a repressão ao comunismo, entre outras, apresentam fortes consequências no Brasil. Em 1955 Juscelino Kubistscheck assumiu a presidência do país e iniciou um período de desenvolvimento industrial com grandes investimentos estrangeiros em todo o país. A passagem para a economia urbano-industrial se torna irreversível. Com o Golpe de Estado, em 1964, o país passa a experimentar crises sucessivas que provocaram um grande endividamento externo. Os reflexos dessas crises, como a migração campo-cidade, o desemprego, e o grande crescimento demográfico das cidades, coincidem com o processo de decadência do polo industrial na cidade e na região. Outras regiões, no estado e no país, oferecem mais e melhores vantagens aglomerativas. Com o passar dos anos, cada vez mais as industrias passam a sofrer com as dificuldades econômicas da cidade, atingindo seu ápice na década de 1990. A partir desse momento, a região, que até então possuía um grande status e importância na economia, passou a ser de certa forma desprezada.

A área delimitada para estudo, mais recentemente, juntamente com o abandono da atividade industrial e portuária, passou a sofrer um processo de degradação física e socioeconômica. Armazéns e fábricas abandonadas passaram a ser ocupadas pelos antigos trabalhadores das fábricas locais, e por uma parcela da população de baixa renda que sobrevivia da pesca, corte e comercialização de juncos, uma planta típica da região. Com esta nova dinâmica socioespacial, a sociedade literalmente "virou as costas" para o canal São Gonçalo, direcionando não só suas principais atividades socioeconômicas, como também sua expansão urbana em direção oposta ao canal.

Atualmente, com uma população de 346 mil habitantes (IBGE, 2010), Pelotas configura-se como uma cidade de porte médio, localizada na encosta sudeste do estado do Rio Grande Sul, Brasil, às margens do Arroio Pelotas e do Canal São Gonçalo, área de transição entre o Planalto Sul-Rio-Grandense (também chamado de Escudo Cristalino) e a Planície Costeira Sul-Brasileira (IBGE, 1986). A figura 1 apresenta a localização da cidade de Pelotas no Brasil e no Rio Grande do Sul. 


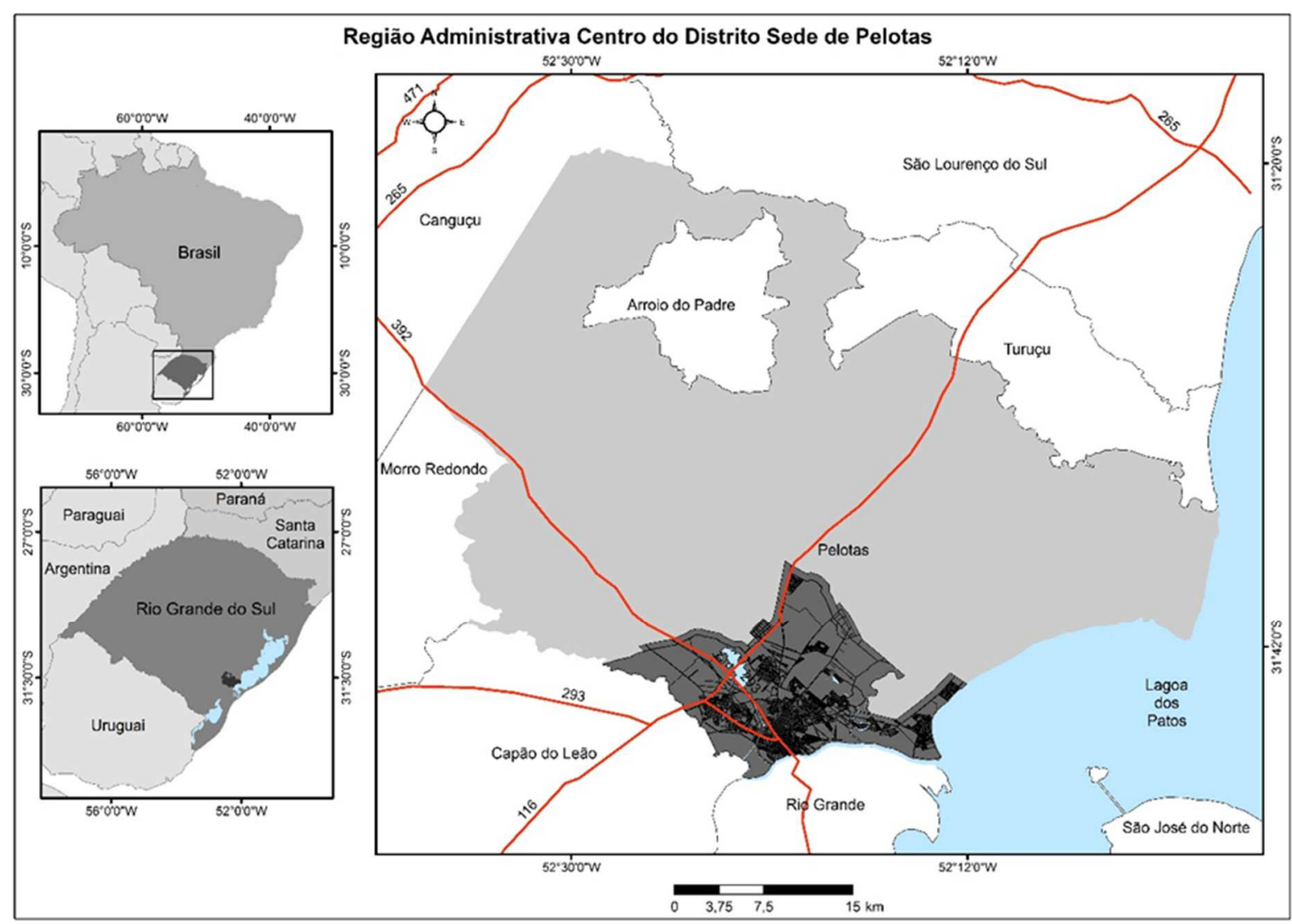

Figura 1 - Localização do município de Pelotas: A esquerda-superior a localização do Rio Grande do Sul no Brasil; A esquerda-inferior a localização do municipio de Pelotas no Rio Grande do Sul. Ao centro, o perimetro urbano da cidade de Pelotas.

Fonte: Elaborado por Allan Oliveira, com base no Mapa Urbano, III Plano Diretor de Pelotas, 2008.

Do ponto de vista administrativo, o Brasil é um país federado, organizado pela totalidade dos seus distintos entes: União, Estados, Distrito Federal e Municípios. Por sua vez, os municípios são divididos em distritos, sendo o distrito sede correspondente à cidade, ou seja, à área urbana do município. A organização da estrutura interna das cidades é regulamentada por Lei Municipal. De acordo com a Lei Municipal № 5.502 de 2008, que instituiu o III Plano Diretor de Pelotas, a área urbana do município organiza-se em Macrorregiões (ou Regiões Administrativas), Mesorregiões e Microrregiões, que correspondem ao que comumente são reconhecidos como os grandes bairros da cidade, sendo o perímetro urbano da cidade dividido em sete regiões administrativas: Centro, Fragata, Barragem, Três Vendas, Areal, São Gonçalo e Laranjal.

A localidade, onde hoje está a Região Administrativa São Gonçalo, durante décadas, vivenciou o abandono e a desvalorização imobiliária. Grande parte da área era constituída por terrenos de campos às margens do Canal São Gonçalo, que se mantiveram enquanto 
local de preservação da natureza. A Universidade Federal de Pelotas (UFPel), ainda na década passada, iniciou um processo de aquisição dos prédios utilizados por antigas fábricas e depósitos existentes na área, tendo em vista sua revitalização para aproveitamento como unidades acadêmicas. Gradualmente, uma nova função passou a ser identificada em parte da área, agora também reconhecida como ligada à produção do conhecimento.

Esta revitalização atraiu não só novos olhares para este espaço esquecido, como também investimentos imobiliários, comerciais e públicos que acabaram ressignificando novamente a região. Trata-se de uma ocupação de vazios urbanos que estavam à espera de uma valorização. Entretanto, o interesse econômico e imobiliário trouxe consigo diversos conflitos territoriais, pois a (re)produção do espaço urbano não pode ser entendida apenas como um resultado histórico: ela cria e (re)produz territórios próprios. Neste sentido, o território não é apenas ritual e simbólico, é também o local de práticas ativas e atuais, por intermédio das quais se afirmam e vivem as identidades" (Haesbaert, 1999, p. 169).

\subsection{Territorialidades e Identidades}

Do ponto de vista teórico, se entende a realidade em uma análise de pertencimento ao modo de produção capitalista, o que nos permite considerar a questão da sobrevivência de determinadas relações sociais de produção nos termos de sua permanência. Trata-se, aqui, de entender o modo pelo qual determinadas relações de produção se transformaram ao longo do tempo para permitir a continuidade de um mesmo processo de dominação. Partese do entendimento de que o capitalismo, enquanto modo de produção, não permanece o mesmo todo o tempo, mas evolui durante o seu desenvolvimento sendo capaz de ir se transformando para permanecer hegemônico. Entratanto, nas transformações pelas quais passa, alguns de seus elementos são mantidos nos seus caracteres fundamentais, de modo que seja possível identificá-lo enquanto tal, pela essência. Tais mutações só se tornam possíveis porque o modo de produção é capaz de produzir para sua própria reprodução, que na verdade trata-se de uma re-produção, uma vez que o resultado da produção é justamente a condição primeira também de sua reprodução. Assim, a re-produção não pode ser entendida como uma repetição da produção, mas sim como uma produção nova, que toma como base o produto anterior, mas ao refazer-se, transforma-se, produzindo sempre 
para a sua sobrevivência, em contínua transformação. É o que acontece com as relações de produção no capitalismo, que se re-produzem para, mutadas, permanecerem.

$\mathrm{Na}$ análise do processo de re-produção do espaço urbano na cidade de Pelotas, o caso relatado demonstra essas carcaterísticas de um modo de produção, no caso, o capitalista. Sob a inspiração de uma novidade, de uma transformação, da alegoria de algo diferente, se apresenta um projeto que, na sua essência, mantém a lógica hegemônica do privilégio e da obtenção do lucro. A re-produção do bairro aqui estudado, demonstra que a especulção imobiliária é mais forte do que os interesses do Estado em garantir a proteção ambiental de uma área. Torna-se possível concluir que a remoção de pessoas e o correspondente afastamento dessas pessoas de suas origens e identidade são processos naturais resultantes do crescimento das cidades e da necessária produção de mais espaços de moradias.

Como verificado em Raffestin (1993), o território é a "prisão" que o ser humano constrói para si. Assim, verifica-se que o território é uma parcela do espaço geográfico que se constrói a partir do exercício do poder. É uma demarcação social sobre o espaço. Pode variar desde o território do quintal da casa até o território do Estado-Nação. Em todos os casos, há uma manifesta estipulação de limites imposto sobre os demais. A definição pode se tornar mais complexa quando analisamos a manifestação de territórios voláteis, que têm sua existência temporária ou variada no espaço, ou ainda, quando analisamos a situação de territórios em redes e outras situações. Mas, na estrutura interna das cidades, a manifestação mais inequívoca do território se observa nas localidades, vilas e bairros, onde, sob as mais variadas formas, se expressam o poder.

Assim, facilmente distinguimos a área de atuação de uma determinada comunidade, de um grupo ou de uma liderança, principalmente porque essas manifestações do poder entram em choque com outras, delimitando porções no espaço, reconhecidas como o território de cada uma delas.

O território, em si, manifesta a identidade de quem o constrói/inventa. Neste âmbito, a identidade pode ser entendida como um fenômeno espacial construído socialmente e que está diretamente atrelada à subjetividade. Como argumenta Haesbaert (2002), a identidade social liga-se a identidade territorial. Institui-se do relacionamento das pessoas com o território e a construção da noção de pertencimento. É uma relação conflituosa e afetiva 
que transforma um espaço genérico e indeterminado em uma territorialidade particular e específica. É onde nos "sentimos em casa", reconhecemos nossos objetos e executamos nossas ações.

Criamos, ao longo do tempo, uma relação de reconhecimento entre nós e o espaço físico, mesmo quando nos afastamos, ao voltarmos, nos reconhecemos nas (i)materialidades das histórias narradas e pelos referenciais de memória presentes. Trata-se de uma relação arquitetada na trama do cotidiano, ligado ao trabalho, à família e ao lazer. É um sentimento que diz respeito a nós mesmos e nem sempre pode ser comungado com outros na mesma condição, pois uma territorialidade, presentificada na categoria de lugar, no caso da individualidade do pertencer, pode gerar o sentimento de pertencimento ou de estranhamento, definindo nossa identificação ou não.

O bairro, em uma cidade, é fruto da territorialidade e da identidade. Do ponto de vista da estrutura urbana, é reconhecido como a menor unidade de vizinhança da cidade, o qual se delimita territorialmente por suas características físicas, quando são partes claramente identificáveis da cidade, como acontece quando há a existência de limites naturais como um curso d'água (arroio, sanga ou canal, p. ex.) ou artificiais (como no caso de uma ferrovia, estrada ou avenida, p. ex.). Do mesmo modo, a delimitação do bairro também pode se dar em função de sua identidade. Nesse caso, identidade conferida pelas características próprias de uma determinada área da cidade (local de moradia de trabalhadores, existência predominante de comércio ou indústria, p. ex.).

No caso de Pelotas, a Região Administrativa São Gonçalo é uma invenção legal, pois foi criada para fins de planejamento urbano. Neste âmbito, o bairro está delimitado no espaço da área compreendida entre o Arroio Pelotas, à leste, o canal do Pepino (Avenida Juscelino Kubistcheck) à oeste, a Avenida Ferreira Viana, ao norte e o Canal São Gonçalo ao sul.

O principal caráter identitário presente nessa delimitação está justamente na presença e na relação com o canal São Gonçalo, como uma chamada de atenção que busca lembrar a todos da existência desse importante fator geográfico natural, cujo reconhecimento histórico e ambiental deveria remeter ao respeito pelo patrimônio natural da área. Ainda não há, de fato, um reconhecimento fácil da Região Administrativa São Gonçalo como um 
bairro, propriamente, haja vista que várias áreas no seu interior já possuiam uma identidade tal que poderiam constituir, verdadeiramente, bairros.

De acordo com Simon et al. (2017), a Região Administrativa São Gonçalo está assentada,

\begin{abstract}
Nas áreas de planície flúvio-lacustre, originalmente se desenvolvem formações vegetais pioneiras, ou seja, campos inundáveis e banhados. Os banhados são importantes ambientes, pois suportam as quantidades elevadas de precipitação, prolongando o período de chegada da água até os arroios, equilibrando o balanço hídrico regional. Além do mais, sustentam biodiversidade peculiar e registros arqueológicos que explicam a história recente das sociedades que por aqui viveram.
\end{abstract}

De acordo com o IBGE, a população registrada no local, na área delimitada como Região Administrativa São Gonçalo, no Censo de 2010, era de 28.400 habitantes. Mesmo que só tenha sido criada oficialmente em 2008, por ocasião da aprovação do III Plano Diretor, aquela área da cidade possui uma tradição em Pelotas reconhecida pelos relacionamentos sociais construídos ao longo do tempo pelas pessoas que vivem no local em lugares como Anglo, Balsa, Nossa Senhora de Fátima, Navegantes, Cruzeiro do Sul, Humuarama, Marina Ilha Verde, Ambrósio Perret e Chácara da Brigada. Esses lugares, que constituem loteamentos ou urbanizações existentes dentro da Região Administrativa São Gonçalo, são plenamente reconhecidos pela sociedade pelotense. Ou seja, antes de serem moradores do São Gonçalo, já moravam nesses lugares. A ficção jurídica e a denominação para efeitos de planejamento não alteram as territorialidades e as identidades criadas nesse espaço, apenas outorgam um nome diferente do qual estamos acostumados a nos referir. Pode-se fazer uma analogia ao que acontece com o nome e o apelido que damos às pessoas: um é oficial o outro é do dia a dia. Também o nome da Região de Planejamento São Gonçalo, instituído para lembrar o cuidado que se deveria ter com as ocupações naquele local, não teve a capacidade de frear a grande explosão imobiliária que se verificou ali.

Fora os loteamentos consolidados na periferia do Centro, como Fátima, Navegantes e Balsa, todo o resto foi, durante muito tempo, um vazio ocupado pelas enchentes periódicas contidas por diques de drenagem. Depois, foram surgindo outros loteamentos (urbanizações) como Humuarama, Ilha Verde e outros. Mais recentemente o deslocamento da área jurídica do centro tradicional da cidade para o bairro São Gonçalo trouxe para o lugar juízes, promotores e advogados, que passaram a conviver com os moradores e o Shopping Center Pelotas que instalou-se no local como uma grande centralidade comercial e imobiliária capaz de gerar grande fluxo de pessoas. O já movimentado caminho para as 
praias do bairro Laranjal, nas franjas ao sul do bairro Areal, passou a ser cobiçado pelos empreendedores imobiliários, onde uma série de novos lançamentos surgiram naquele trajeto da Avenida Ferreira Viana. Atualmente, as urbanizações Lagos de São Gonçalo, Parque Una I e Parque Una II são os principais loteamentos a ocuparem o que era vazio, estabelecendo um grande conflito com os moradores originais, sobretudo à beira do canal na Estrada do Engenho. O conflito se estabelce em face de que a ocupação feita pelos tradicionais ocupantes se dava por um tipo de habitação orgânica, integrante da própria natureza do lugar. Uma pequena favela constituída por um casario simples, construído com materias de descarte de obras e do lixo urbano. Em contrapartida, os loteamentos que começam a chegar no local são representados por edifícios de negócios e moradia, de alta tecnologia e de uma urbanização contemporânea, que busca privilegiar o compartilhamento de áreas de trabalho e de lazer entre os seus moradores, constituindo um empreendimento voltado para novos moradores. Trata-se de um conflito sócio-espacial gerado pela diferença social entre os ocupantes de áreas contíguas, cujo resultado, em toda a parte, tem se dado com a expulsão dos antigos moradores que não conseguem permanecer ante a fragilidade de sua situação jurídico-política (via de regra são posseiros, ou seja, não são os proprietário legais dos terrenos que ocupam), e da sua condição econômico-social (são pobres, cuja remoção não causa impacto político relevante na sociedade dominante).

\subsection{O Espaço Urbano: Um Campo de Lutas}

O espaço urbano é por excelência um campo de lutas. É justamente na disputa de interesses contraditórios que a produção espacial se constituirá. As diferentes disputas e necessidades sociais, as diferentes formas de apropriação e uso do solo, concebem cidades contraditoriamente alheias às necessidades e utopias de seus habitantes. Tomando como exemplo o empreendimento Parque Una, cuja implantação se dá na Região Administrativa São Gonçalo, em sua concepção original, verificamos a construção de um bairro planejado, espaço de moradia, lazer e trabalho num mesmo local, não somente para seus moradores, como também para a comunidade em geral. O projeto imobiliário é inspirado em autores como François Ascher, Jane Jacobs, Jan Gehl, percursores de teorias de um Novo Urbanismo. Por meio de aparatos publicitários são apresentados benefícios aos futuros moradores do então Parque Una: uma vida moderna, segura, prática, leve e prazerosa, 
concentrada em um espaço pensado e planejado para o convívio entre pessoas. $\mathrm{Na}$ área central do Parque está localizado um lago, uma alusão ao Canal São Gonçalo, com áreas de convivência, quadras poliesportivas, além de calçadas planejadas na mesma altura que as ruas cobertas e suas ciclovias. Os empreendedores afirmam que este local será o "ponto de encontro de toda a cidade", o embrião de uma nova centralidade comercial e imobiliária. $\mathrm{Na}$ figura 2 podemos verificar este heterogêneo espaço ainda em construção.

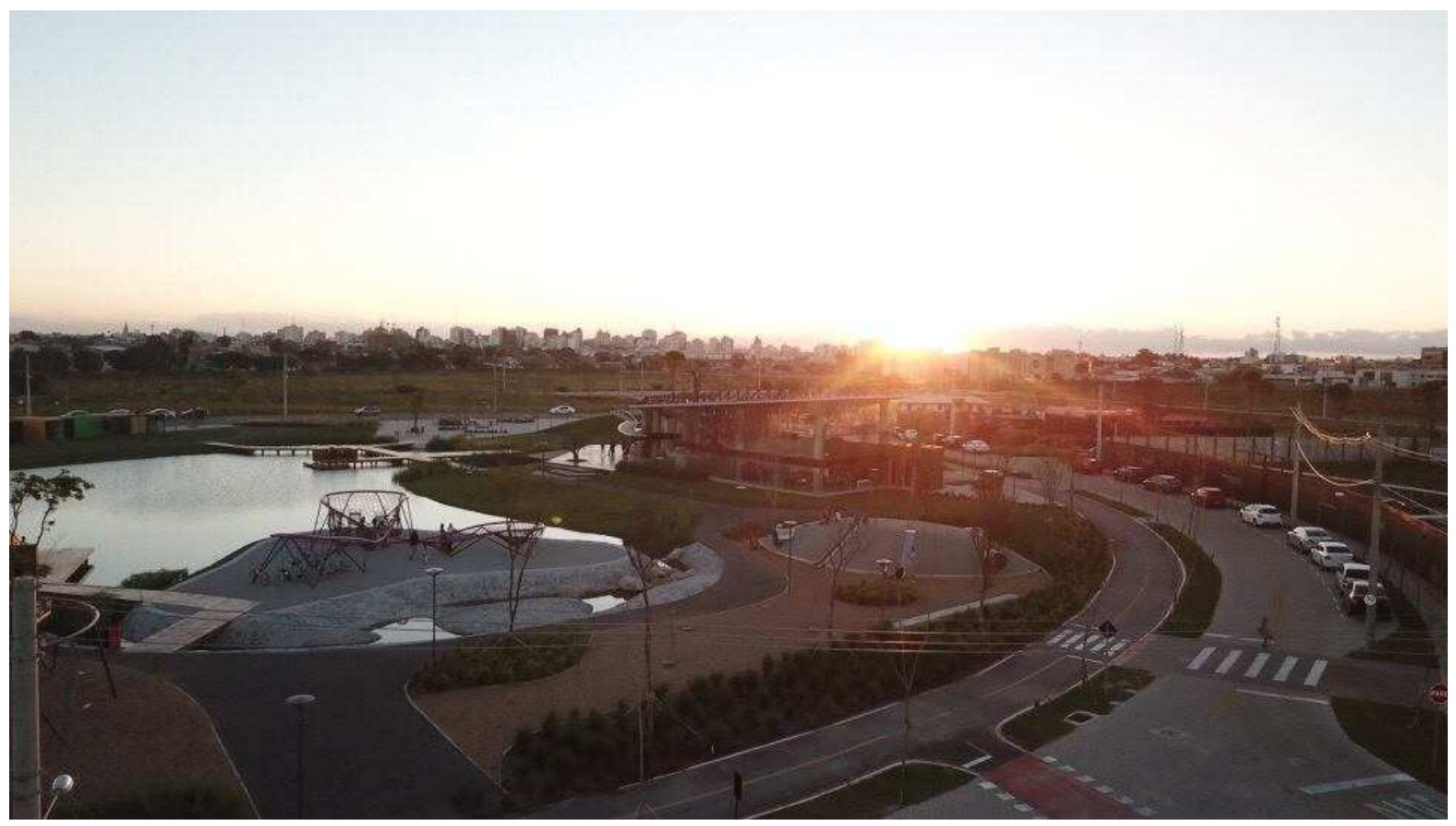

Figura 2 - Parque Una na Região Administrativa São Gonçalo Fonte: Dos autores, 2018.

Uma das mudanças mais importantes no processo de estruturação do espaço urbano é a redefinição do papel do centro, destacado na forma de centralidades urbanas. Pintaudi (2009) destaca que o centro urbano, aquele que guarda a memória da cidade, histórico, é permanente. Já a centralidade é mutável no tempo e espaço. Com a construção do Parque Una em uma área valorizada pelo Estado e por promotores imobiliários, os investidores já definem que o público-alvo será uma classe média alta, com alto poder aquisitivo. Neste sentido, o questionamento que se faz é: Qual o real alcance do discurso criado para oferta do empreendimento na prática? Ou seja, como um espaço pensado e planejado como um bem privado se transformará em um espaço público equitativo para todas classes sociais?

O espaço produzido sob o signo do capitalismo tem por base a propriedade privada. Enquanto que uma minoria da população vive em condições favoráveis, a grande maioria "sobrevive" em casas bem mais modestas, com recursos limitados. Em suma, os espaços 
que restam a esta parcela da população são os vazios urbanos, onde são construídas casas feitas de madeiras, latas, e restos de materiais, que refletem não só a precariedade das políticas públicas, mas demonstra que a desigualdade espacial é produto da desigualdade social. Os vazios urbanos - tônica nas cidades brasileiras - convivem com recortes extremamente adensados e verticalizados e outros rarefeitos e horizontalizados. Tais vazios podem se relacionar, é verdade, com áreas de preservação permanente, mas na prática, o que se observa são grandes porções de terra mantidas intactas sob a lógica especulativa. Assim, tais vazios "aguardam" novas frentes de expansão urbana, que serão traduzidas por novas infraestruturas e a consequente valorização dos terrenos do entorno. Fruto de uma política de planejamento urbano raramente eficaz, teremos como resultado uma urbanização heterogênea, onde novas parcelas urbanizadas se incorporam no tecido urbano com pouca ou nenhuma conexão com as formas pretéritas, ignorando ainda as especificidades do território. Na Região Administrativa do São Gonçalo, especificamente na Rua Estrada do Engenho, encontra-se uma ocupação que conta com aproximadamente 60 famílias, denominada Ocupação Estrada do Engenho. No local vivem moradores há mais de 20 anos, tendo ocorrido sensível aumento no número de pessoas a partir de 2010. A figura 3 apresenta um panorama da ocupação na rua Estrada do Engenho.

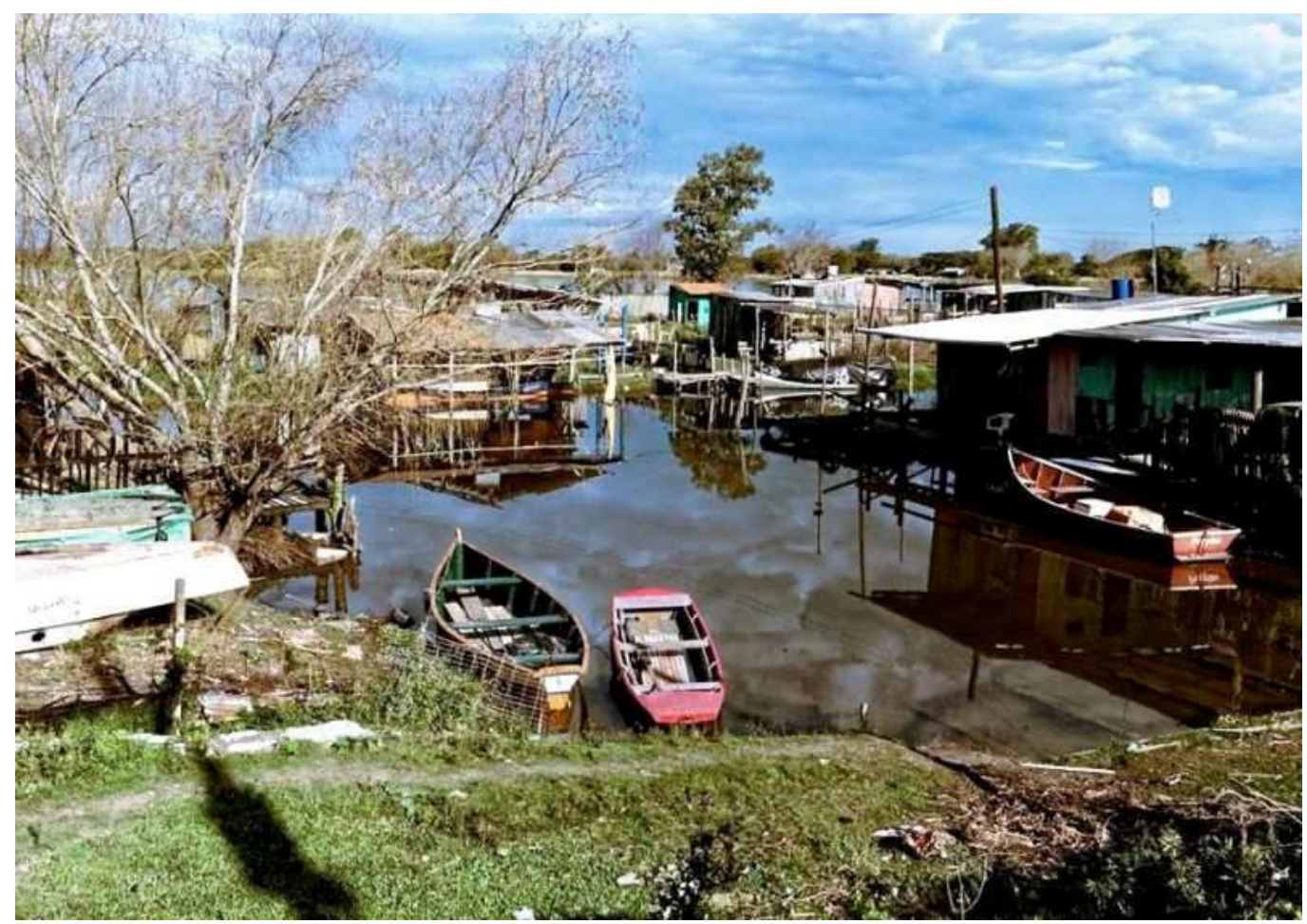

Figura 3 - Ocupação na Rua Estrada do Engenho - Região Administrativa São Gonçalo Fonte: Dos autores, 2018. 
As condições socioespaciais daquela localidade denotam um grande abandono do poder público em prover serviços essenciais, como saneamento básico, iluminação, lazer entre outros. Poucos moradores têm ligação de água e luz, o restante tem que sobreviver com ligações de vizinhas. A Promotoria Pública, no ano de 2014, instaurou um processo contra a Prefeitura Municipal de Pelotas para que se fizesse a reintegração de posse por constar que aquela localidade é uma área de preservação permanente (APP). Ou seja, a posse da área deveria ser recuperada para a municipalidade que não deveria permitir a ocupação face às características paisagísticas da área, a exigir sua preservação no estado natural, protegida da ação antrópica provocada pelos moradores em situação precária no local. No termo de ajustamento de conduta (TAC), equivalente a um acordo firmado entre a Prefeitura e a Promotoria Pública, a prefeitura deveria, até novembro de 2017, ter retirado as pessoas moradoras na estrada do engenho, propondo o deslocamento destes ocupantes para 20 terrenos no bairro Getúlio Vargas (distante cerca de $10 \mathrm{~km}$ ), ação está não concretizada até então.

A resistência da comunidade da estrada do engenho parte do princípio de que primeiro eles criaram um pertencimento em relação com a espacialidade do local. Muitos têm o contato com o lugar a partir da pesca ou serviços navais de pequenas embarcações, o que forma toda uma identidade destes moradores com o território. A remoção destes moradores para o bairro Getúlio Vargas não representa apenas a perda de suas casas, mas sim do seu lugar e da sua identidade. Além disso, fatalmente se instalaria um novo conflito entre a população removida e os habitantes tradicionais do local destinado, pois novamente apareceriam as diferenças entre os moradores tradicionais e os recém chegados. A luta dos moradores é pela permanência no local, para que se tenha um projeto de urbanização e construções de casas populares, ou para que uma parte dos moradores possam ficar na localidade conhecida como Vila dos Pescadores, reconhecida como uma Área Especial de Interesse Social(AEIS), no III Plano Diretor da Cidade, classificação que permitiria ao Poder Pùblico facilidades na regularização fundiária e na urbanização da área. O restante dos moradores poderiam ir para um terreno nas proximidade, em frente dos Veleiros Saldanha da Gama, para que eles possam continuar morando na região do canal São Gonçalo. No processo movido para a reintegração de posse naquele local, são especificados apenas os integrantes 
da ocupação, enquanto outros sujeitos, na mesma situação de irregularidade, não são citados, claramente em virtude de que a condição dos usuários do Clube de Veleiros, e dos casarões na mesma área, próximo da estrada do Passo dos Negros, é socialmente melhor. O que pode justificar essa intenção é o fato de que essa região é muito valorizada pelo capital imobiliário e pelo poder público, como uma área de instalação de crescente classe urbana como os que se observam nos empreendimentos Lagos do São Gonçalo, Parque Una e Parque Una II. O que se percebe no movimento de tentativa de retirada dos moradores da ocupação Estrada do Engenho, é que atrás do discurso de proteção ambiental, vem a força do poder econômico imobiliário, graças à especulação experimentada na área.

Com o empreendimento Lagos do São Gonçalo, já consolidado na região há alguns anos, e os empreendimentos Parque Una e Parque Una II ainda em construção, não podemos fazer um estudo do real impacto que estas transformações socioeconômicas e espaciais trarão às comunidades locais, porém, podemos dizer que tanto os novos ocupantes do Parque Una, quanto os moradores do Bairro São Gonçalo, têm pouca ou nenhuma identificação com a história do local, e sequer criam uma identidade com esse espaço. É uma característica dos atuais loteamentos fechados se isolarem do seu entorno. Com a valorização na região do São Gonçalo, e com os novos moradores, já podemos notar um conflito de territorialidade e identidade entre os novos e os antigos moradores. Até mesmo de permanência, no caso dos moradores da Estrada do Engenho. Todos os benefícios que os empreendimentos Lagos do São Gonçalo, Parque Una e Parque Una II oferecem a uma camada social especifica, como lazer, cultura, infraestrutura urbana, são vendidos como valores de troca por parte do capital imobiliário. Essas pessoas terão que pagar um elevado custo para ter esses benefícios. É a dinâmica imobiliária transformando o direito à cidade em mercadoria.

\section{Conclusões}

Segundo Henry Lefebvre, o espaço não é algo pronto, ele é produzido pelos seres humanos. Esta leitura nos faz pensar a (re)produção do espaço urbano a partir da dialética e do materialismo histórico, onde este é condição, meio e produto da ação humana ao longo do tempo. Um espaço de continuidades e descontinuidades, onde a realidade aparentemente 
simultânea representa uma acumulação desigual de tempos, ansiando virtualidades, possibilidades colocadas ao futuro. Esta virtualidade no caso estudado se constitui em um movimento de resistência. A reprodução do capital desterritorializa pessoas, nega suas identidades, provocam processos conflitivos entre removidos e empreendedores imobiliários e acabam promovendo a resistência como forma de reação a esses processos que buscam a imposição dos desígnios do mercado. A resistência dos moradores no Bairro São Gonçalo configura um conflito territorial onde a principal luta a ser traçada é a garantia ao direito de expressão na cidade, de construírem a sua identidade no espaço urbano. Podemos nos questionar em relação a qual identidade o poder imobiliário e o poder público municipal querem construir no bairro São Gonçalo. Antes mesmo de se instalarem os novos ocupantes, por meio dos empreendimentos, a região já preservava uma identidade de classe trabalhadora, de baixa renda, muito semelhante aos primeiros ocupantes da região, que eram os negros, trabalhadores escravos nas charqueadas. Podemos interpelar também porque os novos habitantes não criam uma identidade com o bairro. Na verdade, os novos habitantes criam uma identidade, só que diferente da existente no local, estabelecendo, assim, o conflito. Este processo tende a destruir a memória do lugar, substituindo-a por uma nova percepção da própria cidade. Podemos constatar que esta dinâmica não é exclusiva do bairro São Gonçalo, (re)produzindo-se em outros espaços da cidade. Assim, concluímos que a luta não se restringe somente aos moradores da Região São Gonçalo, mas sim de todos os trabalhadores e trabalhadoras dos bairros periféricos da cidade de Pelotas, aos quais diariamente é negado o direito de expressar sua identidade na cidade.

\section{Referências bibliográficas}

BRASIL. Lei n.o 12651/2012, 25 de maio de 2012. Dispõe sobre proteção de vegetação nativa. Diário Oficial [da] República Federativa do Brasil. Brasília, DF.

HAESBAERT, Rogério. (1999). Identidades Territoriais. In: CORRÊA, Roberto Lobato e ROSENDAHL, Zeny (Orgs.). Manifestações da Cultura no Espaço. Rio de Janeiro: UERJ.

HAESBAERT, Rogério. Territórios Alternativos. São Paulo: Contexto, 2002.

IBGE. Atlas das Cidades. Brasil, 1986.

IBGE. Censo Populacional 2010. Brasil, 2010.

LEFEBVRE, Henri. O Direito à Cidade. São Paulo: Centauro, 2001. 
PINTAUDI, S. M. Anotações sobre o Espaço do Comércio e do Consumo. In: Carles Carreras; Suzana Mara Miranda Pacheco. (Org.). Cidade e Comércio - A rua comercial na perspectiva internacional. 1 ed. Rio de Janeiro: Armazém das Letras, 2009, v. 1, p. 55-6.

PREFEITURA DE PELOTAS. Lei n.ํ 5.502, de 11 de setembro de 2008.

RAFFESTIN, Claude. Por uma Geografia do Poder. São Paulo: Ática, 1993.

SANTOS, Milton. A Natureza do Espaço. 2. São Paulo: Hucitec, 1991.

SIMON, A. L. H.; LOPES, A. L. O.; SPIRONELLO, R. L. Dinâmica de Cobertura e Uso da Terra e as Intervenções na Rede de Drenagem da Bacia do Arroio Sanga Funda (Rio Grande do Sul - Brasil). GEOGRAFIA (RIO CLARO. IMPRESSO), v. 42, 2017

VIEIRA, S. G. O Centro Vive. O Espetáculo da Revalorização do Centro de São Paulo. Tese de Doutorado. Rio Claro: Geografia, 2002.

VIEIRA, Sidney Gonçalves. A cidade fragmentada. O planejamento e a segregação social do espaço urbano em Pelotas. Pelotas, RS: Ed. da UFPel, 2005. 